\title{
Recognizing the role of victim supports in building and maintaining healthy and safe communities
}

\author{
Sarah Johnston-Way* and Sue O'Sullivan*
}

\begin{abstract}
The effects of crime can persist for years and can have life-long implications for some victims. The physical and emotional impact, alongside practical problems, point to the need for the rehabilitation of victims and their families in order to avoid or mitigate some of the long-term negative impacts of crime and, in so doing, contribute significantly to community well-being. The meaningful integration of assistance and supports for victims of crime into community safety strategies can contribute not only to increased public safety, but also to a host of other positive outcomes such as considerable cost savings, improvements in public health, and increased confidence in the criminal justice system. Currently, available research and metrics highlighting these linkages remain scarce, pointing to an important opportunity to strengthen the availability of data and research related to the experience of victimization and the impacts and outcomes of interventions with victims of crime. This paper explores the contribution of providing victim supports for building and maintaining healthy and safe communities, and will identify possible research directions to strengthen understanding in this area.
\end{abstract}

Key Words Impact of victimization, victim services, crime prevention, cost of crime, repeat victimization, community safety

Journal of CSWB. 2016 Aug;1(2):12-15

www.journalcswb.ca

\section{INTRODUCTION}

Successful strategies to build and maintain community safety rely upon an understanding of the value of social inclusion and the necessity of supporting and building connections with all members of society, including vulnerable groups, children and youth, offenders and victims, while using a variety of initiatives that respond to the particular needs of each (Standing Senate Committee on Social Affairs, Science and Technology, 2013).

Some community safety strategies have focused largely on crime prevention by targeting individuals with risk factors present that may contribute to a higher likelihood of committing crime (Public Safety Canada, 2016). However, arguably less attention has been paid to the potential linkages between providing victims with supports and services and building and maintaining healthy and safe communities.

The meaningful integration of assistance and supports for victims of crime into community safety strategies can contribute not only to increased public safety, but also to a host of other positive outcomes such as: considerable cost savings, improvements in public health, and increased confidence in the criminal justice system. Currently, available research and metrics highlighting these linkages remain scarce, pointing to an important opportunity to strengthen the availability of data and research related to the experience of victimization and the impacts and outcomes of interventions with victims of crime.

This paper will explore the contribution of providing victim supports for building and maintaining healthy and safe communities, and will identify possible research directions to strengthen understanding in this area.

\section{NATURE AND EXTENT OF CRIME IN CANADA}

To understand victimization in Canada, it is perhaps useful to describe the nature and extent of crime. Although Canada has seen a steady decline in the volume and severity of criminal activity since the early 1990s, preventing crime and associated victimization should remain a priority for Canadian communities. 2014 marked the lowest police-reported crime rate since 1969. However, levels of crime and victimization in Canada are still a concern. 5.6 million people, aged 15 
and older, reported that they or their household had been the victim of at least one of the eight crimes (sexual assault, robbery, physical assault, theft of personal property, break and enter, theft of motor vehicle or parts, theft of household property, and vandalism) measured by the 2014 General Social Survey (GSS) (Perreault, 2015).

At the same time, roughly 1.8 million Criminal Code offences were reported by police services in 2014 (Perreault, 2015). Although this number represents approximately 33,000 fewer reported incidents than in 2013, police-reported crime rates for violations of child pornography, terrorism, extortion, identity fraud, sexual violations against children, abduction, fraud, and motor vehicle theft all increased from 2013 to 2014 (Boyce, 2015). One-third of Canadian census metropolitan areas saw an increase in either the volume and severity of police-reported crime or the volume of crime relative to the population size. Furthermore, the total number of homicides increased slightly from 512 in 2013 to 516 in 2014.

It should be noted that these numbers focus on crime that has been reported to police or identified in victimization surveys in which only a limited sample of people are interviewed about specific types of crimes. According to the 2014 GSS, just $31 \%$ of criminal incidents were brought to the attention of the police in 2014. Furthermore, only 5\% of sexual assaults were reported to the police (Perreault, 2015). Underreporting of child abuse and spousal violence is also common (National Working Group on Crime Prevention, 2007).

These numbers demonstrate that there is still much to be done to further reduce crime, prevent victimization, and make communities safer. A preventative and victim-centered approach to crime will promote safer and healthier communities, and thus reduce crime and victimization.

\section{THE IMPACT OF CRIME ON VICTIMS AND THEIR COMMUNITIES}

Such an approach is necessary given the significant impact on victims, and the communities in which they reside. Criminal victimization has physical, psychological, and financial consequences, and creates circles of impact that include not only victims and offenders and their families, but also their communities and society as a whole.

There are both tangible and intangible costs associated with crime. Tangible costs can be assigned a financial value and include medical and mental health services, criminal justice, victim services, protective services, and the value of stolen or damaged property. Intangible or non-monetary costs are generally more difficult to measure and include pain and suffering, fear of crime, hindering economic development, and lost quality of life. The total annual costs of crime in Canada have been estimated at $\$ 99.6$ billion, of which $\$ 82.5$ billion, or $83 \%$, is borne by victims. Of this amount, $\$ 14.3$ billion is directly attributable to tangible costs such as medical attention, hospitalizations, lost wages, missed school days, and stolen/damaged property. Productivity losses represent $47 \%$ of the tangible costs borne by victims, followed by stolen/damaged property (42.9\%) and health care costs $(10.1 \%)$. Total intangible costs (including pain and suffering and loss of life) are $\$ 68.2$ billion (Department of Justice Canada, 2013).
A 2011 study of over 400 families bereaved by homicide in the United Kingdom (Casey, 2011) further illustrates the devastating impact on families, revealing that bereavement through crime is often followed by loss of employment, the breakdown of relationships and mental health problems. Specifically:

The vast majority $(80 \%+)$ had suffered trauma-related symptoms;

Three-quarters suffered depression;

One in five became addicted to alcohol;

$100 \%$ said that their health was affected in some way, and eight out of ten $(83 \%)$ said their physical health was affected;

- Nearly six in ten (59\%) found it difficult to manage their finances following the bereavement;

One in four stopped working permanently;

One in four had to move home;

Three-quarters said it affected their other relationships; $44 \%$ who experienced relationship problems with a spouse said it led to divorce or separation;

$59 \%$ had difficulty managing their finances; and

A quarter $(23 \%)$ gained sudden responsibility for children as a result of the killing.

These results demonstrate that the effects of crime can persist for years and can have life-long implications for some victims. The physical and emotional impact, alongside practical problems, should signal a call to action to society in terms of focusing on the rehabilitation of victims and their families in order to avoid or mitigate some of the long-term negative impacts of crime and, in so doing, contribute significantly to community well-being.

Accordingly, the overall financial and social costs of crime are increasingly important for society and government, as crime places a significant social and financial burden on Canadians. Given these significant impacts, a proactive, victim-centered approach is necessary.

\section{SUPPORTING VICTIMS AS A KEY COMPONENT OF SAFE COMMUNITIES}

Assistance and supports provided to victims following an experience of victimization can play an important role in helping to reduce the impact of crime by providing victims with supports to address the trauma they may have experienced as a result of the crime committed against them.

Common forms of assistance available in Canada include: protection and crisis services, information to assist victims with the courts and justice system and support their participation in the system, medical-related assistance, shelter-related services and assistance with securing compensation (Allen, 2014). These types of supports can assist in reducing vulnerability to repeat victimization, and can also be instrumental in helping victims to reclaim their lives, restore their productivity, and help them to avoid developing concurrent issues such as poor mental health and addictions (National Crime Prevention Council, 2016). The United Nations Centre for International Crime Prevention suggests that victim supports are integral to the promotion of victim restoration, which contributes to the maintenance and improvement of quality of life in 
communities (United Nations. Centre for International Crime Prevention, 1999).

Further, a large proportion of crimes are committed against people who have been previously victimized, a phenomenon known as repeat victimization. Several studies show a link between abuse experienced during childhood and both an increased risk of victimization in adulthood (Parks, 2011; Reid, 2009; Desai, 2002) and an increased likelihood of having contact with police (Boyce, 2015). The Canadian Victimization Survey of the Statistics Canada General Social Survey, which is collected at five-year intervals, measures victimization not reported to police. The most recent survey, conducted in 2014, suggests that people who suffered child maltreatment were more likely to be victims of crime. Overall, people who experienced child maltreatment recorded a rate of violent victimization more than double that of people who did not experience such abuse (125 per 1,000 compared to 55). Both physical and sexual abuse experienced during childhood was associated with higher rates of violent victimization (Perreault, 2015).

Additionally, a study of victimization and repeat victimization in Canada, based on 1999 General Social Survey data, demonstrated that more than half of all respondents $(57.8 \%)$ reported experiencing at least one criminal incident during their lifespan. More than one in eight (13.5\%) were victimized more than once, and these repeat victims experienced over half $(54 \%)$ of all offences. The study offers a conclusion that this concentration of victimization warrants "victimbased preventive measures" (Gabor and Mata, 2004), which supports the idea that a preventative and victim-centered approach to crime is necessary.

There is great potential for victim-centered approaches to be integrated within current crime prevention and community safety strategies. Current best practices in crime prevention employ multi-disciplinary approaches-with representatives across social services including health, education, child protection, justice, addictions counseling, etc.- - to address risk factors that may increase an individual's likelihood of engaging in criminal activity. Models, whereby coordinated and integrated responses through the mobilization of these resources are used to address situations facing individuals with elevated risk factors identified across a range of service providers, have been recognized as good practice, as seen in the adoption of the Hub model in communities across Saskatchewan (Saskatchewan Building Partnerships to Reduce Crime, 2016).

If victims and their families, who may or not be at risk of committing crime but whose health and well-being is identified as at risk, are similarly targeted for intervention by multi-disciplinary social service teams to provide supports that help to address the impacts of crime (as noted above), there is significant potential to improve community wellbeing. In so doing, the potential for positive impacts and outcomes in terms of public health, cost savings in the realm of health and social services by avoiding the development of concurrent issues, and contributions to the prevention of repeat victimization, become more likely. This presents an important opportunity for communities to increase safety and well-being by integrating victims into existing crime prevention and community safety strategies.

\section{OPPORTUNITIES FOR STRENGTHENING RESEARCH AND DATA RELATED TO VICTIMIZATION}

While the logic behind such integration seems clear, there is a lack of research and data to support these claims. The meaningful collection of data-and, indeed, research related to interventions specific to victims of crime-remains somewhat limited in Canada, pointing to an opportunity to strengthen such research in this area.

In addition, the recent introduction and coming into force of Bill C-32, the Victims Bill of Rights Act ${ }^{\mathrm{a}}$, provides a strategic opportunity to align victimization metrics to support evidence-based policy and decision-making related to victims of crime. This legislation creates the Canadian Victims Bill of Rights (CVBR), which provides statutory rights at the federal level for victims of crime for the first time in Canada's history. The CVBR establishes statutory rights for victims to information, protection, participation, and seek restitution, and it ensures that a complaint process is in place for breaches of these rights by a federal department or agency. A victim can exercise the rights in the CVBR while an offence is being investigated or prosecuted and while the offender is subject to the corrections or conditional release process.

Recognizing both the strategic opportunity to ensure that important data related to victims' experiences with the criminal justice system is captured in relation to the CVBR, and the need to improve the availability and quality of victimization metrics more broadly, the Office of the Federal Ombudsman for Victims of Crime has partnered with the Canadian Centre for Justice Statistics (CCJS) of Statistics Canada who will lead a data mapping and feasibility project. The project will outline research needs and opportunities related to victims of crime, and propose a strategy to develop relevant victimization metrics. Data needs will be identified through consultations with organizations who work in the area of victims research and policy development. The primary objective is to identify metrics that will inform policy and program design related to victim issues. The end product will be a strategic roadmap providing options for short, mid-, and long-term data projects that respond to identified research gaps and contribute to a deeper understanding of the needs of victims and the outcomes of interventions aimed at meeting their needs.

\section{CONCLUSIONS}

In addition to the harm and trauma they suffer as a result of the crime committed against them, victims of crime also bear a disproportionate amount of social and financial costs following their experience of victimization.

Recognizing the importance and prioritizing the maintenance of quality of life for victims through victim assistance and supports is necessary to build and maintain healthy and safe communities. Positive effects in the areas of public cost savings, increased public health, and increased confidence in the criminal justice system are the likely results. Available research and metrics highlighting these linkages remain

Some amendments to the Corrections and Conditional Release Act have no yet come into force, and will on a day or days to be fixed by Order in Council. 
scarce, pointing to an important opportunity to strengthen the availability of data and research related to the experience of victimization and the impacts and outcomes of interventions with victims of crime.

Ensuring that victims are informed, considered, protected, and supported throughout their journey, from time of crime through any experiences with the criminal justice system and over the longer term, should remain an important goal across systems and services interacting with victims. This is important because we know that, when victims are treated with dignity and respect, they are more likely to be satisfied with the criminal justice system, regardless of the outcome. Arguably, this satisfaction is important because it can be linked to confidence in the criminal justice system (Wemmers, Van der Leeden, \& Steensma, 1995).

We can do more to work together to ensure that victims and families get the help they need and that the impacts of crime are minimized, while recognizing these efforts as significant contributions to the objective of building and maintaining healthy and safe communities.

\section{CONFLICT OF INTEREST DISCLOSURES}

Sarah Johnston-Way is a full-time employee of the Office of the Federal Ombudsman for Victims of Crime. Sue O'Sullivan is the Federal Ombudsman for Victims of Crime, appointed by Order in Council pursuant to the Public Service Employment Act of Canada as a special advisor to the Minister of Justice.

\section{AUTHOR AFFILIATIONS}

${ }^{*}$ Office of the Federal Ombudsman for Victims of Crime, Ottawa, ON.

\section{REFERENCES}

Allen, M. (2014) Victim Services in Canada, 2011/2012. Statistics Canada. Juristat, 34(1). Catalogue no. 85-002-X

Boyce, J. (2015) Police-reported crime statistics in Canada, 2014. Statistics Canada. Juristat, 35(1). Catalogue no. 85-002-X

Casey, L. (2011). Review into the Needs of Families Bereaved by Homicide. Ministry of Justice UK. Retrieved from: https://www.justice.gov.uk/ downloads/news/press-releases/victims-com/review-needs-of-familiesbereaved-by-homicide.pdf

Department of Justice Canada (2013).Victims Rights: Enhancing Criminal Law Responses to Better Meet the Needs of Victims of Crime in Canada.
Retrieved from: http://www.justice.gc.ca/eng/ci-jp/victims-victimes/ vrights-droitsv/l

Desai, S., Arias, I., Thompson, M. P., et al. (2002). Childhood victimization and subsequent adult revictimization assessed in a nationally representative sample of women and men. Violence Vict. 17(6):639-653.

Gabor, T and Mata, F. (2004). Victimization and repeat victimization over the life span: A predictive study and implications for policy. Int Rev Victimol. 10(3):193-221

National Crime Prevention Council. (2016). Strategy: Victim Assistance Services. Retrieved from: http://www.ncpc.org/topics/home-andneighborhood-safety/strategies/strategy-victim-assistance-services

National Working Group on Crime Prevention. (2007). Building a Safer Canada: First Report of the National Working Group on Crime Prevention. Institute for the Prevention of Crime, University of Ottawa. Retrieved from: https://www.cacp.ca/communicating-on-crime-prevention.html?assst_id

Parks, S.E., Kim, K.H., Day, N.L., et al. (2011). Lifetime self-reported victimization among low-income, urban women: The relationship between childhood maltreatment and adult violent victimization. J Interpers Violence. $6(6): 1111-1128$

Perreault, S. (2015). Criminal Victimization in Canada, 2014. Statistics Canada. Juristat. 35(1). Catalogue no. 85-002-X.

Public Safety Canada. (2016). Supporting the Successful Implementation of the National Crime Prevention Strategy. Retrieved from: https://www. publicsafety.gc.ca/cnt/rsrcs/pblctns/spprtng-mplmtn/index-en.aspx\#+3

Reid, J. A. \& Sullivan, C. J. (2009). A model of vulnerability for adult sexual victimization: The impact of attachment, child maltreatment, and scarred sexuality. Violence Vict. 24(4):485-501

Saskatchewan Building Partnerships to Reduce Crime. (2016). "HUB and Core Model." Retrieved from: http://saskbprc.com/index.php/2014-08-2520-54-50/the-hub-cor-mode

Standing Senate Committee on Social Affairs, Science and Technology. (2013). In from the Margins, Part II: Reducing Barriers to Social Inclusion and Social Cohesion. Parliament of Canada. Retrieved from: http://www.parl.gc.ca/Content/SEN/Committee/411/soci/rep/ rep26jun13ExecSummary-e.pdf

United Nations Office for Drug Control and Crime Prevention, Centre for International Crime Prevention. (1999). Handbook on Justice Victims: On the Use and Application of the Declaration of Basic Principles of Justice for Victims of Crime and Abuse of Power. Retrieved from: https://www.unodc. org/pdf/criminal_justice/UNODC_Handbook_on_Justice_for_victims.pdf

Wemmers, J., Van der Leeden, R., \& Steensma, H. (1995). What is procedural justice: criteria used by Dutch victims to assess the fairness of criminal justice procedures. Social Justice Res. 8(4):329-350. 